\title{
Successful administration of measles-rubella-mumps vaccine by graded challenge in a case with anaphylaxis after prior vaccination
}

\author{
Tuba Tuncel, M.D. ${ }^{a}$, Ozlem Sancakli, M.D. ${ }^{b}$ and Ece Ozdogru, M.D. ${ }^{b}$
}

\begin{abstract}
Egg allergy is one of the most common food allergies during childhood along with cow's milk allergy. The measles-mumpsrubella (MMR) vaccine is included in the pediatricimmunization schedule and contains egg protein. The currently accepted opinion is that the MMR vaccination should be done in a single dose under medical observation in patients with egg allergy. Although it is reported that the MMR vaccine is safe for that patients, there are some patients who developed anaphylaxis. Generally, the development of anaphylaxis after the previous vaccination is reported as a contraindication. We present a successful administration of MMR vaccine by gradually increased doses for a patient who developed anaphylaxis after the previous vaccination.

Key words: anaphylaxis, child, egg allergy, measles-mumps-rubella vaccine.
\end{abstract}

http:/ /dx.doi.org/10.5546/aap.2017.eng.e89

To cite: Tuncel T, Sancakli O, Ozdogru E. Successful administration of measles-rubella-mumps vaccine by graded challenge in a case with anaphylaxis after prior vaccination. Arch Argent Pediatr 2017;115(2):e89-e91.

\section{INTRODUCTION}

Egg allergy is one of the most common food allergies during childhood along with cow's milk allergy. ${ }^{1}$ The measles-mumps-rubella (MMR) vaccine is included in the pediatric immunization schedule and contains egg protein. ${ }^{2}$ The vaccination with MMR has been proven to be safe and effective and anaphylactic reaction is rare. ${ }^{3,4}$

a. Izmir Katip Celebi University Medical Faculty, Department of Pediatrics, Division of Pediatric Allergy and Immunology, Izmir Tepecik Training and Research Hospital, Department of Pediatrics. Izmir, Turkey.

b. Izmir Tepecik Training and Research Hospital, Department of Pediatrics. Izmir, Turkey.

E-mail address:

Tuba Tuncel, M.D.: ttuncel@yahoo.com.tr

Funding: None.

Conflict of interest: None.

Received: 5-23-2016

Accepted: 10-11-2016
Although it is reported that the MMR vaccine is also safe for the patients with egg allergy, there are some patients who developed anaphylaxis after MMR vaccine ${ }^{5}$. Herein, we present a successful administration of MMR vaccine by gradually increased doses for a patient who developed anaphylaxis after vaccination with MMR.

\section{Case report}

The patient was evaluated in her first visit to the allergy clinic at 9 months old. The patient's history showed that when she was 5 months old, she presented redness and swelling around the lips and itchy rashes on the eyes, face and body, wheezing and cough, after the consumption of a cow's milk containing formula. It was reported that after yoghurt and egg were given at different times, similar reactions were seen. She was evaluated by a pediatrician and a diet without egg and milk was advised, although no laboratory investigations were carried out. The family has withheld foods that contain milk and eggs, and experienced no trouble. When she was 9 months old, she was vaccinated with MMR vaccine and within 10 minutes she experienced redness, itches, wheezing and shortness of breath; she was given nebulized albuterol and epinephrine in the emergency room. The patient had been directed to our clinic by the emergency room doctor with a suspicion of food allergy and post-vaccination allergic reactions. During the visit, she had no complaint and her physical examination was normal. The complete blood count and blood biochemical analysis were normal. The reactions in the skin and the respiratory system in the patient's history caused by milk, egg and the MMR vaccine were evaluated as compatible with anaphylaxis. Skin prick test was performed and an induration of $3 \times 3 \mathrm{~mm}$ with positive control, $5 \times 5 \mathrm{~mm}$ with egg yolk, 7x7 $\mathrm{mm}$ with egg whites, and $5 \times 5 \mathrm{~mm}$ with cow's milk was determined. Prick-to-prick test with gelatin was negative. The patient was diagnosed with cow's milk and egg allergy without challenge due to the anaphylaxis which has developed after the food intake and the history and laboratory findings complying 
with food allergies. The patient was given a diet without any milk and eggs. The parents were taught how to read labels and also an epinephrin auto-injector was prescribed. When the patient reached 12 months, the skin prick tests were performed again and it was seen that the egg and milk sensitivity persisted. The patient was evaluated for the second dose of MMR which is for the $12^{\text {th }}$ month of life. MMR vaccination was planned for the patient after the allegy tests with the vaccine solution. After the prick test performed with the MMR vaccine solution (1:1) (Priorix ${ }^{\circledR}$ Glaxo Smith Kline) was negative, an intradermal test was performed and it was positive with a $5 \times 5 \mathrm{~mm}$ induration. Therewith, the vaccination was decided to be done with graded challenge. The total of $0.5 \mathrm{ml}$ vaccine were administered as $0.01,0.04,0.10,0.15$ and $0.20 \mathrm{ml}$ doses every 20 minutes. No reaction was seen in the patient following the five step vaccination.

\section{DISCUSSION}

Cow's milk and egg allergies are the most common reasons of food allergies among children. ${ }^{1}$ Avoidance of the foods that cause the allergic reaction is the base of the treatment in patients with food allergies. ${ }^{6}$ The administration of egg containing vaccines particularly MMR to the patients with egg allergy has been discussed. In the earlier publications, it was advised that the skin test should be performed with the vaccine followed by the vaccination with the incremental doses. ${ }^{7}$ However, later studies indicated that MMR vaccination is safe for children with egg allergy, and gelatin may be responsible for the reactions. ${ }^{8-11}$ The currently accepted opinion is that the MMR vaccination should be done in a single dose under medical observation. ${ }^{2,4,12}$ Nevertheless, there are patients who developed anaphylaxis following the MMR vaccine. ${ }^{4,13}$ In our patient, based on detailed history and laboratory investigations, it is considered that the egg content of MMR may be responsible for the anaphylaxis after vaccination.

Until 2011, MMR vaccine was administrated at two doses as 12 months and 6 years old in Turkey. ${ }^{14}$ Then, following the immigration from neighboring countries to Turkey, a rise in the measles cases was seen and the first dose of the vaccination pulled to the age of 9 months. The vaccination is repeated at 12 months because it does not provide enough immunity. In our case, anaphylaxis was developed after the MMR vaccine in the $9^{\text {th }}$ month. The risk of recurrence of the anaphylaxis with second dose was present due to the fact that the period between the two vaccinations was very short and tolerance was not developed. However, the second dose of MMR vaccination was decided when the risk of measles is considered. Although the development of anaphylaxis after the previous vaccination is reported as a contraindication, there was also a suggestion that the vaccination can be administered gradually after the skin test. ${ }^{15}$ But there is no detailed information in the literature. For this purpose, prick and intradermal tests was performed with the MMR vaccine solution and the intradermal test was positive. Thereupon vaccination was carried out on five steps in total. There were not any problems presented after the vaccination.

Anaphylaxis may develop after the MMR vaccine in the cases with egg allergy as in our patient. Therefore, vaccination should be done in the center where the treatment of anaphylaxis can be carried out and the patients should be observed after the vaccination. If anaphylaxis develops, graded challenge may be an option for other doses. This case is presented in order to emphasize that the MMR vaccine could be administered in divided doses without any reaction even in the cases with anaphylaxis after the vaccination.

\section{REFERENCES}

1. Nwaru BI, Hickstein L, Panesar SS, Roberts G, et al. EAACI Food Allergy and Anaphylaxis Guidelines Group. Prevalence of common food allergies in Europe: a systematic review and meta-analysis. Allergy 2014;69(8):992-1007.

2. American Academy of Pediatrics. Measles. In: Pickering L ed. Red Book. 2012. Report of The Committee on Infectious Disease. $29^{\text {th }}$ ed. ELK grove Village, IL: American Academy of Pediatrics, 2012.P.489-500.

3. D'Souza RM, Campbell-Lloyd S, Isaacs D, Gold M, et al. Adverse events following immunisation associated with the 1998 Australian Measles Control Campaign. Commun Dis Intell 2000;24(2):27-33.

4. McLean HQ, Fiebelkorn AP, Temte JL, Wallace GS, Centers for Disease Controland Prevention. Prevention of measles, rubella, congenital rubella syndrome, and mumps, 2013: summary recommendations of the Advisory Committee on Immunization Practices (ACIP). MMWR Recomm Rep 2013;62(RR-04):1-34.

5. FirıncıF,UysalP, TuncelT,Arikan AyyildizZ, etal. Yumurta allerjisi olan bir olguda kızamık-kızamıkçık-kabakulaka 1sı sonrası anafilaksi (poster presentation p17) Turk Pediatri Ars 2010;45:175.

6. Sampson HA, Aceves S, BockSA, James J, et al. Food allergy: a practice parameter update-2014. J Allergy Clin Immunol 2014;134(5):1016-25.e43.

7. Herman JJ, Radin R, Schneiderman R. Allergic reaction to measles (rubeola) vaccine in patients hypersensitive to egg protein. J Pediatr 1983;102(2):196-9.

8. Freigang B, Jadavji TP, Freigang DW. Lack of adverse 
reactions to measles, mumps, and rubella vaccine in eggallergic children. Ann Allergy 1994;73(6):486-8.

9. James JM, Burks AW, Roberson PK, Sampson HA. Safe administration of the measles vaccine to children allergic to eggs. N Engl J Med 1995;332(19):1262-6.

10. Patja A, Mäkinen-Kiljunen S, Davidkin I, Paunio M, et al. Allergic reactions to measles-mumps-rubella vaccination. Pediatrics 2001;107(2):E27.

11. Cerecedo Carballo I, Dieguez Pastor MC, BartoloméZavala B, Sánchez Cano M, et al. Safety of measles-mumpsrubella vaccine (MMR) in patients allergic to eggs. Allergol Immunopathol (Madr) 2007;35(3):105-9.

12. Khakoo GA, Lack G. Recommendations for using MMR vaccine in children allergic to eggs. BMJ2000;320(7239):92932 .
13. Yavuz ST, Sahiner UM, Sekerel BE, Tuncer A, et al. Anaphylactic reactions to measles-mumps-rubella vaccine in three children with allergies to hen's egg and cow's milk. Acta Paediatr 2011;100(8):e94-6.

14. Sağlık Bakanlı̆̆g Temel Sağlık Hizmetleri Genel Müdürlüğü, Genişletilmiş Bağışıklama Programı Genelgesi: 13.03.2009/7941 [Accessed on: December 12, 2015 ] Available in: https://www. saglik.gov.tr

15. National Advisory Committee on Immunization (NACI). Supplementary statement MMR vaccine and anaphylactic hypersensitivity to egg or egg-related antigens. Can Commun Dis Rep 1996;22(14):113-5. 